LINGUA, Vol. 14, No. 2, September 2017

p ISSN: 1979 9411; e ISSN: 2442 238X

Http://lingua.pusatbahasa.or.id; Email: presslingua@gmail.com

Center of Language and Culture Studies, Surakarta, Indonesia

Fauziah, Syaid Anisak; Kamal, Mustofa; Djatmika \& Sumarlam. 2017. Perbedaan antara Klausa Subordinatif Bahasa Indonesia dan Bahasa Inggris. Lingua (2017), 14(2): 309 324.

\title{
PERBEDAAN ANTARA KLAUSA SUBORDINATIF BAHASA INDONESIA DAN BAHASA INGGRIS
}

\author{
Anisak Syaid Fauziah, Mustofa Kamal, Djatmika, Sumarlam \\ Universitas Sebelas Maret, Jl. Ir. Sutami 36A, Surakarta, Indonesia \\ Email: fauziah_syaid@yahoo.com; mustafakemalaljombangi@gmail.com
}

\begin{abstract}
The aim of this study was to describe the difference between subordinate in Indonesian and in English viewed from subordinate clause theory from Jim Miller. This study used qualitative descriptive approach. Primary data of this study were written texts containing sentences and clauses in English and Indonesian the corpus of which was selected from academic texts. Data were collected using record. Segmenting immediate constituent was used to analyze the data. The research revealed that Indonesian has neither elliptic conjunction in all relative and adverbial clauses nor non-finite subordinate clauses. English has no elliptic conjunction only in relative clauses showing possessiveness and all adverbial clauses except for time and result but has non-finite subordinate clauses. Indonesian has no relative clause elliptic conjunction non-finite subordinate clause. English relative clause elliptic conjunction is available and empty elliptic conjunction in all adverbial clauses appear. English has non-finite subordinate clauses.
\end{abstract}

Keywords: subordinate clause, conjunction, ellipsis, non-finite

Klausa antar bahasa di dunia mempunyai kesamaan umum. Kesamaan umum tersebut dipelajari dalam studi linguistik. Karena ada 'kesamaan umum', terdapat perbedaan-perbedaan. Perbedaan-perbedaan tersebut merupakan kekhasan tiap-tiap bahasa. Dalam kesempatan ini, perbedaan antara klausa Bahasa Indonesia dan Inggris akan dikaji.

Sebelum mengkaji lebih jauh perbedaan antara klausa Bahasa Indonesia dan Inggris, dipaparkan definisi klausa. Klausa merupakan tataran sintaksis sebelum kalimat yang konstruksinya bersifat predikatif (mengandung predikat) (Chaer, 2007:231). Sesuai dengan sifat predikatifnya, komponen minimal pembentuk klausa bisa berupa hanya satu verba atau frasa verbal (Verhaar, 2010:162). Setelah diuraikan definisi klausa, kekhasan klausa subordinatif Bahasa Indonesia dan Bahasa Inggris akan dibahasa pada paragraf selanjutnya.

Kekhasan klausa subordinatif Bahasa Indonesia mencakup kurang berterimanya pola elipsis konjungsi dan tidak adanya klausa non-finit. Kurang berterimanya pola elipsis konjungsi dalam klausa Bahasa Indonesia tidak mempunyai alasan ilmiah. Dikatakan tidak mempunyai alasan ilmiah karena kekurangberterimaan pola elipsis tersebut hanya menyangkut masalah kefamiliaran. Tingkat kefamiliaran penggunaan 
LINGUA, Vol. 14, No. 2, September 2017

p ISSN: 1979 9411; e ISSN: 2442 238X

Http://lingua.pusatbahasa.or.id; Email: presslingua@gmail.com

Center of Language and Culture Studies, Surakarta, Indonesia

Fauziah, Syaid Anisak; Kamal, Mustofa; Djatmika \& Sumarlam. 2017. Perbedaan antara

Klausa Subordinatif Bahasa Indonesia dan Bahasa Inggris.

Lingua (2017), 14(2): 309 324.

pola elipsis konjungsi dalam klausa subordinatif Bahasa Indonesia sangat rendah. Misalnya, klausa Haris puja pada frasa nomina Juwita Haris puja akan terasa mengganjal meskipun pemahamannya masih berterima. Ini akan berbeda ketika konjungsi yang tidak dielipsis di dalam klausa tersebut, Juwita yang Haris puja.

Berikut ini adalah kronologi penyebab tidak adanya klausa non-finit dalam Bahasa Indonesia. Verba finit adalah "bentuk verba yang dibatasi oleh kala dan dalam beberapa bahasa menunjukkan kesesuaian dengan persona" (Kridalaksana, 1993:227). Dari definisi tersebut, yang menjadikan Bahasa Indonesia tidak mempunyai verba finit adalah tidak adanya 'kala'. Kridalakasana mendefinisikan kala sebagai "pembedaan bentuk verba untuk menyatakan perbedaan waktu atau jangka perbuatan atau keadaan; biasanya dibedakan antara kala lampau, kala kini, dan kala mendatang" (1993:91). Karena Bahasa Indonesia tidak mempunyai kala, bentuk verbanya tidak berubah kapanpun waktu pemakaiannya. Misalnya, kata menendang tidak akan berubah ketika digunakan dalam klausa Arif kemarin menendang bola, Arif sekarang menendang bola, dan Arif besok menendang bola. Hal tersebut, selanjutnya, berdampak pada tidak adanya jenis klausa subordinatif non-finit dalam Bahasa Indonesia.

Sebaliknya, Bahasa Inggris memiliki pola elipsis konjungsi klausa subordinatif dan klausa subordinatif non-finit sebagai kekhasannya. Tingkat kefamiliaran penggunaan pola elipsis konjungsi klausa subordinatif cukup tinggi dalam bahasa Inggris. Kontruksi seperti having had a laounch, she goes to the office dan Barron I really love sangat sering ditemui dalam Bahasa Inggris. Bahkan, pola elipsis subjek klausa subordinatif juga ada seperti pada contoh pertama, having had.... Tentunya, semakin banyak konstituen yang dielipsis, semakin banyak pula syarat ketentuan yang harus dipenunhi kontruksi tersebut (salah satunya: subjek antara klausa subordinatif dan klausa utama harus sama).

Berikut ini adalah kronologi penyebab adanya klausa non-finit dalam Bahasa Inggris. Bahasa Inggris memiliki baik verba finit maupun kala. Kala bahasa ini terdiri dari kala lampau, kala kini, dan kala mendatang. Verba bahasa ini berubah-ubah sesuai dengan kalanya. Misalnya, kata to kick akan berubah ketika digunakan dalam klausa Arif kicked a ball yesterday, Arif kicks a ball now, dan Arif will kick a ball tomorrow. Hal tersebut, selanjutnya, berdampak pada adanya jenis klausa subordinatif non-finit dalam Bahasa Inggris.

Dalam menemukan research gap, peneliti menggunakan beberapa jurnal yang relevan sebagai berikut. Pertama, jurnal berjudul Urutan Klausa dalam Kalimat Majemuk Subordinatif Bahasa Indonesia: Kajian dari Perspektif Sintaksis dan Wacana oleh Praptomo Baryadi dari Universitas Gajah Mada memberikan hasil penelitian bahwa dari perspektif sintaksis, klausa-kluasa subordinatif sebelah kanan menduduki fungsi objek, pelengkap, subjek dan adverbia sementara yang sebelah kiri fungsi adverbial saja. Dari perspektif wacana, klausa-kluasa subordinatif sebelah kanan hanya mengandung informasi yang berhubungan dengan klausa utama (main clause) dan tidak berhubungan secara langsung dengan kalimat sebelumnya. Sebaliknya, yang sebelah kiri mengandung informasi yang berhubungan dengan kalimat sebelumnya. 
LINGUA, Vol. 14, No. 2, September 2017

p ISSN: 1979 9411; e ISSN: 2442 238X

Http://lingua.pusatbahasa.or.id; Email: presslingua@gmail.com

Center of Language and Culture Studies, Surakarta, Indonesia

Fauziah, Syaid Anisak; Kamal, Mustofa; Djatmika \& Sumarlam. 2017. Perbedaan antara Klausa Subordinatif Bahasa Indonesia dan Bahasa Inggris.

Lingua (2017), 14(2): 309 324.

Persaman jurnal oleh Praptomo Baryadi dengan jurnal ini adalah keduanya sama-sama meneliti klausa subordinatif. Hanya saja, pembahasan klausa subordinatif dalam jurnal Praptomo Baryadi berfokus pada urutan dan juga berhubungan dengan perspektif wacana.

Kedua, jurnal berjudul Pola Urutan Frasa pada Klausa Nominal Bahasa Inggris dan Bahasa Indonesia oleh Dian Rivia Himmawati dari Universitas Negeri Surabaya membuahkan hasil bahwa (1) keberadaan partikel dalam urutan frasa Bahasa Indonesia membuat urutan berubah menjadi predikat-subjek dan (2), sebaliknya, urutan frasa Bahasa Inggris sangat rapat sehingga keberadaan partikel dalam tata bahasanya tidak penting. Persaman jurnal oleh Dian Rivia Himmawati dengan jurnal ini adalah keduanya sama-sama meneliti klausa subordinatif. Hanya saja, pembahasan klausa subordinatif dalam jurnal Dian Rivia Himmawati berfokus pada klausa nomina dan pola urutan frasa.

Ketiga, jurnal berjudul Tipe Dan Pola Klausa Subordinatif Bahasa Indonesia oleh Ratna Djuwita B. dari Institut Teknologi Bandung menyajikan hasil berupa (1) klausa subordinatif adalah klausa yang disertai konjungsi dan dapat menjadi konstituen dari sebuah kalimat majemuk, (2) klausa subordinatif secara umum berfungsi sebagai keterangan, objek, atau pelengkap, dan (3) klausa subordinatif yang berfungsi sebagai keterangan mencakup waktu (time), pengandaian (condition), tujuan (purpose), pertentangan (concession), sebab-akibat (reason/cause), dan cara (manner). Persaman jurnal oleh Djuwita B. dengan jurnal ini adalah keduanya sama-sama meneliti klausa subordinatif. Hanya saja, pembahasan klausa subordinatif dalam jurnal Djuwita B. berfokus pada satu bahasa saja, Bahasa Indonesia. Di samping itu, teori yg digunakan Djuwita B. juga berbeda dengan teori yang digunakan peneliti dalam jurnal ini.

Penelitian ini menggunakan teori klausa subordinatifnya Jim Miller. Dalam An Introduction to English Syntax (2002), Jim Miller membedakan klausa dalam kalimat kompleks menjadi klausa utama (main clause) dan klausa subordinatif (subordinate clause) (2002:63). Klausa utama bisa berdiri sendiri sementara klausa subordinatif tidak. Klausa ini butuh menempel pada sebuah klausa utama atau kata benda. Ketika menempel pada klausa utama, klausa subordinatif ada kalanya mengisi fungsi subjek, objek, dan keterangan sedangkan ketika menempel pada kata benda, dia menjadi penjelas (modifikator). Selain itu, klausa subordinatif juga menempel pada kata sifat di mana dia menjadi penjelasnya. Mengenai macam umumnya, klausa subordinatif dibagi menjadi klausa pelengkap, klausa relatif, dan klausa adverbia. Ditinjau dari finitnya, klausa subordinatif dibagi menjadi klausa subordinatif finit dan non-finit. Pembedaan secara khususnya akan dipaparkan dalam pembahasan. Penelitian ini bertujuan menjelaskan perbedaan antara klausa bahasa Indonesia dan bahasa Inggris khususnya klausa subordinatif.

\section{METODE}

Penelitian ini menggunakan rancangan analisis isi dengan pendekatan kualitatif sebagai pijakan analisis data. Analisis isi dalam penelitian ini bertujuan mengkaji 
korpus dalam teks tertulis berupa tuturan berbentuk kata, frase, kalimat dan wacana yang memiliki konteks klausa subordinatif.

Data penelitian ini adalah klausa subordinatif beserta konteksnya. Konteks yang dimaksud adalah segala konstituen yang masih berhubungan dengan klausa subordinatif dan terlibat dalam analisis. Sumber data penelitian ini berupa teks yang didapat dari percakapan sehari-hari berupa fakta dalam karya-karya tertulis dan lisan.

Metode simak digunakan dalam penyediaan data penelitian ini. Menyimak tidak hanya berkaitan dengan penggunaan bahasa secara lisan tetapi juga secara tertulis (Mahsun, 2014:92). Teknis dasar yang digunakan adalah teknik sadap. Sebagai teknik lanjutan, penelitian ini menggunakan teknik catat. Data dalam penelitian ini berupa data kebahasaan. Data kebahasaan berupa kata-kata yang dianalisis dengan metode agih yang alat penentunya justru dari bagian bahasa yang bersangkutan itu sendiri (Sudaryanto, 1993:15).

Metode analisis yang dipakai adalah teknik Bagi Unsur Langsung (BUL). BUL bekerja dengan cara membagi unsur-unsur pembentuk data dan konteksnya secara bertahap sampai pada tingkat yang dimaksud oleh sebuah penelitian (Sudaryanto, 1993:15). Berkaitan dengan penelitian ini, unsur terbesar data dan konteksnya berupa kalimat. Kalimat tersebut selanjutnya dibagi menjadi beberapa klausa. Tiap-tiap klausa kemudian dibagi lagi menjadi beberapa fungsi. Tiap-tiap fungsi pada tahap berikutnya dibagi menjadi beberapa frasa. Tiap-tiap frasa dibagi lagi menjadi beberapa kata.

\section{HASIL DAN BAHASAN}

Berikut ini adalah temuan bentuk-bentuk klausa berbahasa Indonesia dan Inggris yaitu empat bagian utama tersebut terdiri dari klausa pelengkap, klausa relatif, klausa adverbia, dan klausa non-finit. Beberapa dari empat bagian utama mempunyai bagianbagian lagi sedangkan beberapa lainnya tidak. Sebelum beranjak ke empat bagian utama, peneliti terlebih dahulu memberikan analisis yang memaparkan klausa subordinatif dan klausa utama secara umum.

\section{Analisis Klausa Subordinatif (Subordinate Clause)}

Analisis klausa subordinatif menjelaskan mengenai kalimat dalam bahasa Indonesia dan kalimat dalam bahasa Inggris yang memiliki unsur kalimat. Hasil analisis disajikan berikut ini.

\section{Bahasa Indonesia}

Klausa subordinatif dalam contoh (1) dikutip dari teks berbahasa Indonesia dan disajikan pada Tabel 1.

$$
\text { Ketika Susi memasak nasi, Dina datang. }
$$

Tabel 1. Klausa Subordinatif

\begin{tabular}{|l|l|l|l|l|l|}
\hline Ketika & Susi & memasak & nasi, & Dina & datang. \\
\hline Konjungsi & S & P & O & S & P \\
\hline \multicolumn{2}{|l}{ Klausa Subordinatif (Subordnate Clause) } & \multicolumn{2}{l|}{ Klausa Utama (Main Clause) } \\
\hline
\end{tabular}


Data pada tabel 1 terdapat 2 klausa. Klausa pertama berupa klausa subordinatif Ketika Susi memasak nasi sementara klausa kedua berupa klausa utama Dina datang. Posisi klausa subordinatif mendahuui klausa klausa utama. Klausa subordinatif memiliki fungsi subjek, predikat, dan objek sedangkan klausa utama memiliki fungsi subjek dan predikat saja. Klausa subordinatif diawali dengan konjungsi sementara klausa utama tidak.

Sebuah klausa dikategorikan subordinatif karena, dari segi keindependenan, dia tidak bisa beridiri sendiri. Dari segi signifikansi keberadaan, klausa ini tidak wajib ada dalam suatu kalimat. Dari segi konstituen pembentuk, klausa ini memiliki ciri konjungsi yang tidak dimiliki klausa utama.

\section{Bahasa Inggris}

(2) When Susi is cooking rice, Dina comes.

Tabel 2. Klausa Subordinatif

\begin{tabular}{|c|c|c|c|c|c|c|c|}
\hline When & Susi & is & cooking & rice, & Dina & \multicolumn{2}{|c|}{ comes. } \\
\hline Konjungsi & $\mathrm{S}$ & $\mathrm{F}$ & $\mathrm{P}$ & $\mathrm{O}$ & $\mathrm{S}$ & $\mathrm{F}$ & $\mathrm{P}$ \\
\hline \multicolumn{5}{|c|}{ Klausa Subordinatif (Subordnate Clause) } & \multicolumn{3}{|c|}{ Klausa Utama (Main Clause) } \\
\hline
\end{tabular}

Pada tabel 2 terlihat perbedaan pada contoh bahasa Indonesia, bahasa Inggris mempunyai finit yang menemani masing-masing predikat kedua klausa yang diberi blok warna abu-abu. Dalam klausa subordinatif, subjek diisi oleh kata benda Susi, predikat oleh kata kerja finit: is dan kata kerja utama berkarakter transitif: cooking, dan objek oleh kata benda rice. Dalam klausa utama, subjek diisi oleh kata benda Dina dan predikat oleh kata kerja finit: $-s$ dan kata kerja utama berkarakter intransitif: come.

\section{Klausa Pelengkap (Complement Clause) \\ a. Klausa Pelengkap Nomina}

\section{Bahasa Indonesia}

(3) Gilang berkata bahwa Maman masuk kelas hari ini.

Tabel 3. Klausa Pelengkap Nomina

\begin{tabular}{|l|l|l|l|l|l|l|}
\hline Gilang & berkata & bahwa & Maman & masuk & kelas & hari ini. \\
\hline \multirow{3}{*}{$\mathrm{S}$} & \multirow{5}{*}{$\mathrm{P}$} & Konjungsi & $\mathrm{S}$ & $\mathrm{P}$ & $\mathrm{K}$ & $\mathrm{K}$ \\
\cline { 3 - 6 } & \multicolumn{2}{l}{ O: Klausa Pelengkap Nomina } \\
\hline
\end{tabular}

Pada tabel 3 terdapat klausa pelengkap nomina. Disebut nomina karena klausa ini menempati salah satu fungsi nomina, objek. Dalam klausa pelengkap nomina tersebut, terdapat fungsi subjek, predikat, pelengkap, dan keterangan. Fungsi subjek dalam klausa ini diisi oleh kata benda Maman, fungsi predikat oleh kata kerja berkarakter intransitif masuk, dan fungsi keterangan oleh kata kelas dan sebuah frasa 
nomina hari ini dengan ini sebagai penjelas dan hari sebagai inti. Konjungsi yang menemani klausa ini berupa bahwa yang terletak sebelum Maman.

Klausa ini juga mempunyai pola susunan tanpa konjungsi (konjungsi yang dielipsis) dengan tetap adanya subjek klausa. Pola susunan ini berterima dalam Bahasa Indonesia seperti tampak pada Tabel 4.

Tabel 4. Klausa Pelengkap Nomina

\begin{tabular}{|l|l|l|l|l|l|}
\hline Gilang & berkata & Maman & masuk & kelas & hari ini. \\
\hline \multirow{3}{*}{$\mathrm{S}$} & \multirow{4}{*}{$\mathrm{P}$} & $\mathrm{S}$ & $\mathrm{P}$ & $\mathrm{K}$ & $\mathrm{K}$ \\
\cline { 3 - 6 } & & O: Klausa Pelengkap Nomina & \\
\hline
\end{tabular}

Selain jenis klausa pelengkap nomina dengan konjungsi bahwa, terdapat jenis klausa pelengkap nomina dengan konjungsi kata tanya (siapa, apa, kapan, di mana, dan bagaimana). Dalam klausa jenis ini, fungsi yang ditanyakan akan hilang. Dalam contoh di bawah ini, fungsi yang hilang adalah keterangan waktu karena yang ditanyakan juga keterangan waktu (kapan).

\section{Bahasa Indonesia}

(5) Zaim bertanya kapan kita pergi.

Tabel 5. Klausa Pelengkap Nomina

\begin{tabular}{|l|l|l|l|l|}
\hline Zaim & bertanya & Kapan & kita & pergi. \\
\hline \multirow{3}{*}{$\mathrm{S}$} & \multirow{3}{*}{$\mathrm{P}$} & Konjungsi/K & $\mathrm{S}$ & $\mathrm{P}$ \\
\cline { 3 - 5 } & & O: Klausa Pelengkap Nomina & \\
\hline
\end{tabular}

\section{Bahasa Inggris}

(6) Gilang said that Maman was present that day.

Tabel 6. Klausa Pelengkap Nomina

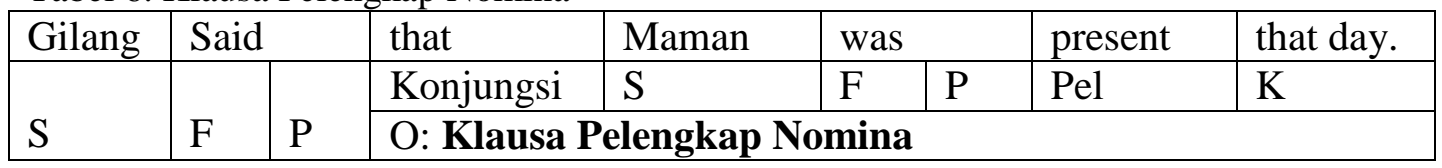

Terdapat klausa pelengkap nomina pada tabel 6. Disebut nomina karena klausa ini menempati salah satu fungsi nomina, objek. Dalam klausa pelengkap nomina tersebut, terdapat fungsi subjek, predikat, pelengkap, dan keterangan. Fungsi subjek dalam klausa ini diisi oleh kata benda Maman, fungsi predikat oleh kata kerja finit yang tersembunyi dalam kata kerja utama bentuk lampau tak berarturan sehingga tidak diketahui ciri kala lampaunya (-d/-ed) was, fungsi pelengkap oleh kata sifat present, dan fungsi keterangan oleh sebuah frasa nomina that day dengan that sebagai penjelas dan day inti. Konjungsi yang menemani klausa ini berupa that yang terletak sebelum Maman. 
Klausa pelengkap nomina ini juga mempunyai pola susunan tanpa konjungsi (konjungsi yang dielipsis) dengan tetap adanya subjek klausa. Pola susunan ini berlaku dalam Bahasa Inggris.

Tabel 7. Klausa Pelengkap Nomina

\begin{tabular}{|c|c|c|c|c|c|c|c|}
\hline Gilang & \multicolumn{2}{|c|}{ Said } & Maman & & & present & that day. \\
\hline \multirow[b]{2}{*}{$\mathrm{S}$} & \multirow[b]{2}{*}{$\mathrm{F}$} & \multirow[b]{2}{*}{$\mathrm{P}$} & $\mathrm{S}$ & $\mathrm{F}$ & $\mathrm{P}$ & Pel & $\mathrm{K}$ \\
\hline & & & \multicolumn{5}{|c|}{ O: Klausa Pelengkap Nomina } \\
\hline
\end{tabular}

Selain jenis klausa pelengkap nomina dengan konjungsi that, terdapat jenis klausa pelengkap nomina dengan konjungsi kata tanya (who, whom, what, when, where, dan how). Dalam klausa jenis ini, fungsi yang ditanyakan akan hilang. Dalam contoh di bawah ini, fungsi yang hilang adalah keterangan waktu karena yang ditanyakan juga keterangan waktu (when).

$$
\begin{aligned}
& \text { Zaim asked when we went. } \\
& \text { (Zaim bertanya kapan kita pergi.) }
\end{aligned}
$$

Tabel 8. Klausa Pelengkap Nomina

\begin{tabular}{|l|l|l|l|l|l|l|}
\hline Zaim & \multicolumn{2}{|l|}{ asked } & when & we & went. \\
\hline \multirow{3}{*}{$\mathrm{S}$} & \multirow{3}{*}{$\mathrm{F}$} & \multirow{2}{*}{$\mathrm{P}$} & Konjungsi/K & $\mathrm{S}$ & $\mathrm{F}$ & $\mathrm{P}$ \\
\cline { 4 - 6 } & & & & O: Klausa Pelengkap Nomina & \\
\hline
\end{tabular}

\section{b. Klausa Pelengkap Adverbia}

\section{Bahasa Indonesia}

(9) Saya takut bahwa suatu saat, saya akan melukai hati Danil.

Tabel 9. Klausa Pelengkap Adverbia

\begin{tabular}{|l|l|l|l|l|l|l|l|}
\hline Saya & Takut & bahwa & suatu saat, & saya & akan & melukai & $\begin{array}{l}\text { hati } \\
\text { Danil. }\end{array}$ \\
\hline \multirow{8}{*}{ S } & Inti & Konjungsi & K & S & A & P & O \\
\cline { 2 - 6 } & Frasa Adjektiva & Klausa Pelengkap Adverbia \\
\cline { 2 - 6 } & Pel & \\
\hline
\end{tabular}

Klausa pelengkap adverbia terdapat pada tabel 9. Klausa pelengkap adverbia tersebut bertempat pada frasa adjektiva dan berfungsi sebagai penjelas dari intinya. Fungsi yang ada di dalamnya berupa subjek, predikat, objek, dan keterangan. Subjek diisi oleh kata ganti saya, predikat oleh aspek: akan dan kata kerja utama berkarakter transitif: melukai, objek oleh frasa nomina hati Danil dengan Danil sebagai penjelas dan hati inti, dan keterangan oleh frasa nomina suatu saat dengan suatu sebagai penjelas 
dan saat sebagai inti. Konjungsi yang menemani klausa ini adalah bahwa. Klausa pelengkap ini disebut adverbia karena dia menjelaskan (memodifikatori) inti yang berupa kata sifat dan inti yang berupa kata sifat hanya bisa dijelaskan dengan kata keterangan (adverb), frasa adverbia, dan klausa pelengkap adverbia.

Klausa ini juga mempunyai pola susunan tanpa konjungsi (konjungsi yang dielipsis) dengan tetap adanya subjek klausa. Pola susunan ini berlaku dalam Bahasa Indonesia seperti tampak pada tabel 10.

Tabel 10. Klausa Pelengkap Adverbia

\begin{tabular}{|c|c|c|c|c|c|c|}
\hline Saya & Takut & suatu saat & saya & akan & melukai & hati Danil. \\
\hline \multirow[b]{4}{*}{$S$} & \multirow[b]{2}{*}{ Inti } & $\mathrm{K}$ & $\mathrm{S}$ & A & $\mathrm{P}$ & $\mathrm{O}$ \\
\hline & & \multicolumn{5}{|c|}{ Penjelas: Klausa Pelengkap Adverbia } \\
\hline & \multicolumn{6}{|c|}{ Frasa Adjektiva } \\
\hline & \multicolumn{6}{|l|}{ Pel } \\
\hline
\end{tabular}

\section{Bahasa Inggris}

(11) I am afraid that one day, I will hurt Danil's feeling.

Tabel 11. Klausa Pelengkap Adverbia

\begin{tabular}{|c|c|c|c|c|c|c|c|c|c|}
\hline I & am & & afraid & that & one day, & $\mathrm{I}$ & will & hurt & Danil's feeling. \\
\hline \multirow[b]{4}{*}{$S$} & \multirow[b]{4}{*}{$\mathrm{F}$} & & \multirow[b]{2}{*}{ Inti } & Konjungsi & $\mathrm{K}$ & $\mathrm{S}$ & $\mathrm{F}$ & $\mathrm{P}$ & $\mathrm{O}$ \\
\hline & & & & \multicolumn{6}{|c|}{ Penjelas: Klausa Pelengkap Adverbia } \\
\hline & & & \multicolumn{7}{|c|}{ Frasa Adjektiva } \\
\hline & & $P$ & \multicolumn{7}{|l|}{ Pel } \\
\hline
\end{tabular}

Pada tabel 11 terdapat klausa pelengkap adverbia. Klausa pelengkap adverbia tersebut bertempat pada frasa adjektiva dan berfungsi sebagai penjelas dari intinya. Fungsi yang ada di dalamnya berupa subjek, predikat, objek, dan keterangan. Subjek diisi oleh kata ganti $I$, predikat oleh kata kerja finit: will dan kata kerja utama berkarakter transitif: hurt, objek oleh frasa nomina Danil's feeling dengan Danil's sebagai penjelas dan feeling inti, dan keterangan oleh frasa nomina one day dengan one sebagai penjelas dan day sebagai inti. Konjungsi yang menemani klausa ini adalah that. Klausa pelengkap ini disebut adverbia karena dia menjelaskan (memodifikatori) inti yang berupa kata sifat dan inti yang berupa kata sifat hanya bisa dijelaskan dengan kata keterangan (adverb), frasa adverbia, dan klausa pelengkap adverbia.

Klausa ini juga mempunyai pola susunan tanpa konjungsi (konjungsi yang dielipsis) dengan tetap adanya subjek klausa. Pola susunan ini berlaku dalam Bahasa Inggris ditunjukkan pada tabel 12. 
Tabel 12. Klausa Pelengkap Adverbia

\begin{tabular}{|c|c|c|c|c|c|c|c|c|}
\hline I & an & & afraid & one day, & I & will & hurt & Danil's feeling \\
\hline \multirow[b]{4}{*}{$\mathrm{S}$} & \multirow[b]{4}{*}{$\mathrm{F}$} & \multirow[b]{4}{*}{$\mathrm{P}$} & \multirow[b]{2}{*}{ Inti } & $\mathrm{K}$ & $\mathrm{S}$ & $\mathrm{F}$ & $\mathrm{P}$ & $\mathrm{O}$ \\
\hline & & & & \multicolumn{5}{|c|}{ Penjelas: Klausa Pelengkap Adverbia } \\
\hline & & & \multicolumn{6}{|c|}{ Frasa Adjektiva } \\
\hline & & & \multicolumn{6}{|l|}{ Pel } \\
\hline
\end{tabular}

\section{Klausa Relatif (Relative Clause)}

\section{a. Klausa Relatif Nomina}

\section{Bahasa Indonesia}

Anjing yang aku pukul berlari kencang.

Tabel 13. Klausa Relatif Nomina

\begin{tabular}{|c|c|c|c|c|c|}
\hline Anjing & yang & aku & pukul & berlari & kencang. \\
\hline \multirow[b]{2}{*}{ Inti } & Konjungsi/O & S & $\mathrm{P}$ & \multirow[b]{4}{*}{$\mathrm{P}$} & \multirow[b]{4}{*}{ K } \\
\hline & \multicolumn{3}{|c|}{ Penjelas: Klausa Relatif Nomina } & & \\
\hline \multicolumn{4}{|c|}{ Frasa Nomina } & & \\
\hline \multicolumn{4}{|c|}{ S } & & \\
\hline
\end{tabular}

Klausa relatif ditunjukkan pada tabel 13 . Klausa relatif tersebut bertempat pada frasa nomina dan berfungsi sebagai penjelas dari intinya. Fungsi yang di dalamnya terdiri dari subjek dan predikat. Di dalam klausa ini tidak terdapat objek secara nyata karena objek merujuk pada inti frasa nomina, anjing. Yang menggantikan anjing dalam klausa ini adalah konjungsi yang. Karena yang menggantikan anjing, yang berkelas kata kata ganti (pronoun). Subjek dalam klausa ini diisi oleh kata ganti $a k u$ dan predikat oleh kata kerja berkarakter transitif pukul. Klausa relatif ini disebut nomina karena fungsinya yang tidak ada adalah objek. Objek tersebut digantikan oleh konjungsi yang.

Jika klausa ini dihilangkan konjungsinya, klausa ini akan berkesan aneh karena fenomena penghilangan konjungsi klausa relatif nomina tidak lazim dalam Bahasa Indonesia yang ditunjukkan pada tabel 14 .

Tabel 14. Klausa Relatif Nomina

\begin{tabular}{|l|l|l|l|l|}
\hline Anjing & Aku & pukul & berlari & kencang. \\
\hline \multirow{3}{*}{ Inti } & S & P & \\
\cline { 2 - 3 } & Penjelas: Klausa Relatif Nomina & \multirow{2}{*}{ P } & K \\
\hline S
\end{tabular}

\section{Bahasa Inggris}

(15) The dog which I hit ran fast. 
LINGUA, Vol. 14, No. 2, September 2017

p ISSN: 1979 9411; e ISSN: 2442 238X

Http://lingua.pusatbahasa.or.id; Email: presslingua@gmail.com

Center of Language and Culture Studies, Surakarta, Indonesia

Fauziah, Syaid Anisak; Kamal, Mustofa; Djatmika \& Sumarlam. 2017. Perbedaan antara

Klausa Subordinatif Bahasa Indonesia dan Bahasa Inggris.

Lingua (2017), 14(2): 309 324.

Tabel 15. Klausa Relatif Nomina

\begin{tabular}{|c|c|c|c|c|c|c|}
\hline The dog & Which & I & hit & rar & & fast. \\
\hline \multirow[b]{2}{*}{ Inti } & Konjungsi/O & $\mathrm{S}$ & $\mathrm{F}$ & \multirow[b]{3}{*}{$F$} & \multirow[b]{3}{*}{$\mathrm{P}$} & \multirow[b]{3}{*}{ K } \\
\hline & \multicolumn{3}{|c|}{ Penjelas: Klausa Relatif Nomina } & & & \\
\hline \multicolumn{4}{|l|}{$\mathrm{S}$} & & & \\
\hline
\end{tabular}

Klausa relatif terdapat pada tabel 15 . Klausa relatif tersebut bertempat pada frasa nomina dan berfungsi sebagai penjelas dari intinya. Fungsi yang di dalamnya terdiri dari subjek dan predikat. Di dalam klausa ini tidak terdapat objek secara nyata karena objek merujuk pada inti frasa nomina, dog. Yang menggantikan dog dalam klausa ini adalah konjungsi which. Karena which menggantikan dog, which berkelas kata kata ganti (pronoun). Subjek dalam klausa ini diisi oleh kata ganti $I$ dan predikat oleh kata kerja finit yang tersembunyi dalam kata kerja utama bentuk lampau tak berarturan sehingga tidak diketahui ciri kala lampaunya (-d/-ed) hit. Klausa relatif ini disebut nomina karena fungsinya yang tidak ada adalah objek. Objek tersebut digantikan oleh konjungsi which.

Jika klausa ini dihilangkan konjungsinya, klausa ini tidak akan terkesan aneh karena penghilangan konjungsi klausa relatif nomina terjadi dalam Bahasa Inggris.

Tabel 16. Klausa Relatif Nomina

\begin{tabular}{|l|l|l|l|l|l|}
\hline The dog & I & hit & \multicolumn{2}{|l|}{ ran } & fast. \\
\hline \multirow{3}{*}{ Inti } & S & F & & & \\
\cline { 2 - 2 } S & \multicolumn{3}{|l|}{ Penjelas: Klausa Relatif Nomina } & & \\
\cline { 1 - 2 } & & F & P & K \\
\hline
\end{tabular}

\section{b. Klausa Relatif Adjektiva}

\section{Bahasa Indonesia}

(17) Dinda yang bapaknya meninggal sekarang masuk kelas.

Tabel 17. Klausa Relatif Adjektiva

\begin{tabular}{|l|l|l|l|l|l|l|}
\hline Dinda & Yang & bapaknya & meninggal & sekarang & masuk & kelas. \\
\hline \multirow{4}{*}{ Inti } & Konjungsi/Penjelas: Adj & Inti & & & & \\
\cline { 2 - 4 } & S & P & & & \\
\cline { 2 - 6 } S & Penjelas: Klausa Relatif Adjektiva & & & \\
\hline
\end{tabular}

Dalam tabel 17 terdapat klausa relatif. Klausa relatif tersebut bertempat pada frasa nomina dan berfungsi sebagai penjelas dari intinya. Fungsi yang di dalamnya terdiri dari subjek dan predikat. Subjek dalam klausa ini diisi oleh kata benda bapaknya dan predikat oleh kata kerja berkarakter intransitif meninggal. Klausa relatif ini disebut 
adjektiva karena dia menyatakan kepemilikan (possessiveness). Karena menyatakan kepemilikan, konjungsi yang berkelas kata kata sifat.

Klausa relatif ini tidak menerima pola pengelipsisan konjungsi. Ini dikarenan konjungsi yang menyatakan kepemilikan. Kepemilikan dalam kasus ini berfungsi sebgari penjelas dari dan melekat pada inti frasa nomina yang berupa bapaknya.

\section{Bahasa Inggris}

Dinda whose father was dead now is present in the class.

Tabel 18. Klausa Relatif Adjektiva

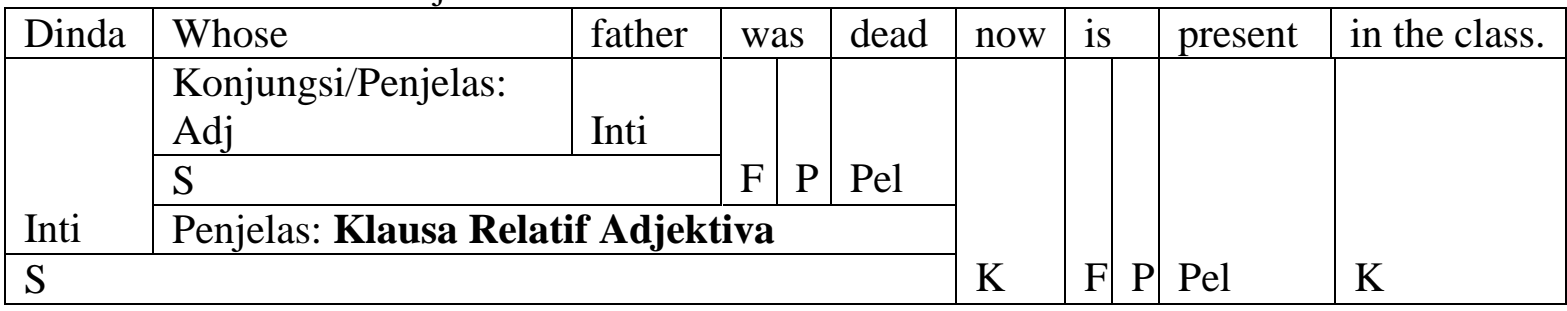

Terdapat klausa relatif pada tabel 16. Klausa relatif tersebut bertempat pada frasa nomina dan berfungsi sebagai penjelas dari intinya. Fungsi yang di dalamnya terdiri dari subjek, predikat, dan pelengkap. Subjek dalam klausa ini diisi oleh kata benda father, predikat kata kerja finit yang tersembunyi dalam kata kerja utama bentuk lampau tak berarturan sehingga tidak diketahui ciri kala lampaunya (-d/-ed) was, dan pelengkap kata sifat present. Klausa relatif ini disebut adjektiva karena dia menyatkan kepemilikan (possessive). Karena menyatakan kepemilikan, konjungsi yang berkelas kata kata sifat.

Klausa relatif ini tidak menerima pola pengelipsisan konjungsi. Ini dikarenan konjungsi whose dalam klausa relatif ini menyatakan kepemilikan. Kepemilikan berfungsi sebagai penjelas dari dan melekat pada inti frasa nomina yang berupa father.

\section{c. Klausa Relatif Adverbia}

\section{Bahasa Indonesia}

Saya hidup di Indonesia di mana saya lahir.

Tabel 18. Klausa Relatif Adverbia

\begin{tabular}{|c|c|c|c|c|c|c|}
\hline Saya & hidup & $\mathrm{di}$ & Indonesia & di mana & saya & lahir. \\
\hline \multirow[b]{5}{*}{$\mathrm{S}$} & \multirow[b]{5}{*}{$\mathrm{P}$} & \multirow[b]{3}{*}{ Pre } & \multirow[b]{2}{*}{ Inti } & Konjungsi/K & $\mathrm{S}$ & $\mathrm{P}$ \\
\hline & & & & \multicolumn{3}{|c|}{ Penjelas: Klausa Relatif Adverbia } \\
\hline & & & \multicolumn{4}{|l|}{ Pel } \\
\hline & & \multicolumn{5}{|c|}{ Frasa Preposisi } \\
\hline & & \multicolumn{5}{|l|}{$\mathrm{K}$} \\
\hline
\end{tabular}


Pada tabel 18 terdapat klausa relatif. Klausa relatif tersebut bertempat pada frasa nomina dan berfungsi sebagai penjelas dari intinya. Fungsi yang di dalamnya terdiri dari subjek dan predikat. Di dalam klausa ini, tidak terdapat keterangan secara nyata karena keterangan merujuk pada inti frasa nomina, Indonesia. Yang menggantikan Indonesia dalam klausa ini adalah konjungsi di mana. Karena di mana menggantikan Indonesia, di mana berkelas kata kata keterangan (adverb). Subjek dalam klausa ini diisi oleh kata ganti saya dan predikat oleh kata kerja berkarakter intransitif lahir. Klausa relatif ini disebut adverbia karena fungsinya yang tidak ada adalah keterangan. Keterangan tersebut digantikan oleh konjungsi di mana.

Jika klausa ini dihilangkan konjungsinya, klausa ini akan berkesan aneh karena fenomena penghilangan konjungsi klausa relatif adverbia tidak lazim dalam Bahasa Indonesia.

Tabel 19. Klausa Relatif Adverbia

\begin{tabular}{|c|c|c|c|c|c|}
\hline Saya & hidup & $\mathrm{di}$ & Indonesia & saya & lahir. \\
\hline \multirow[b]{5}{*}{$S$} & \multirow[b]{5}{*}{$\mathrm{P}$} & \multirow[b]{3}{*}{ Pre } & \multirow[b]{2}{*}{ Inti } & $\mathrm{S}$ & $\mathrm{P}$ \\
\hline & & & & $\begin{array}{lll}\text { Penjelas: } & \text { Klausa } & \text { Relatif } \\
\text { Adverbia } & & \end{array}$ & \\
\hline & & & Pel & & \\
\hline & & Frasa Preposisi & & & \\
\hline & & $\mathrm{K}$ & & & \\
\hline
\end{tabular}

\section{Bahasa Inggris}

(20) I live in Indonesia where I was born.

Tabel 20. Klausa Relatif Adverbia

\begin{tabular}{|c|c|c|c|c|c|c|c|c|}
\hline I & \multicolumn{2}{|c|}{ live } & In & Indonesia & where & $\mathrm{I}$ & was & born \\
\hline \multirow[b]{5}{*}{$S$} & & \multirow[b]{5}{*}{$\mathrm{P}$} & \multirow[b]{3}{*}{ Pre } & \multirow[b]{2}{*}{ Inti } & Konjungsi/K & $\mathrm{S}$ & $\mathrm{F}$ & $\mathrm{P}$ \\
\hline & & & & & \multicolumn{4}{|c|}{ Penjelas: Klausa Relatif Adverbia } \\
\hline & & & & \multicolumn{5}{|l|}{ Pel } \\
\hline & & & \multicolumn{6}{|c|}{ Frasa Preposisi } \\
\hline & $\mathrm{F}$ & & \multicolumn{6}{|l|}{$\mathrm{K}$} \\
\hline
\end{tabular}

Terdapat klausa relative pada tabel 20. Klausa relatif tersebut bertempat pada frasa nomina dan berfungsi sebagai penjelas dari intinya. Fungsi yang di dalamnya terdiri dari subjek dan predikat. Di dalam klausa ini tidak terdapat keterangan secara nyata karena keterangan merujuk pada inti frasa nomina, Indonesia. Yang menggantikan Indonesia dalam klausa ini adalah konjungsi where. Karena where menggantikan Indonesia, where berkelas kata kata keterangan (adverb). Subjek dalam klausa ini diisi oleh kata ganti $I$ dan predikat oleh kata kerja finit: was dan kata kerja utama berkarakter transitif pasif: born. Klausa relatif ini disebut adverbia karena 
fungsinya yang tidak ada adalah keterangan. Keterangan tersebut digantikan oleh konjungsi where.

Jika klausa ini dihilangkan konjungsinya, klausa ini tidak akan berkesan aneh karena fenomena penghilangan konjungsi klausa relatif adverbia lazim dalam Bahasa Inggris. Namun, yang perlu digarisbawahi adalah ketika yang dielipsis berupa konjungsi klausa relatif adverbia yang menyatakan tempat, preposisi in perlu ditambahkan.

Tabel 21. Klausa Relatif Adverbia

\begin{tabular}{|c|c|c|c|c|c|c|c|}
\hline $\mathrm{I}$ & \multicolumn{2}{|c|}{ live } & In & Indonesia & I & was & born in. \\
\hline \multirow[b]{5}{*}{$S$} & \multirow[b]{5}{*}{$\mathrm{F}$} & \multirow[b]{5}{*}{$P$} & & \multirow[b]{2}{*}{ Inti } & $\mathrm{S}$ & $\mathrm{F}$ & $\mathrm{P}$ \\
\hline & & & & & \multicolumn{3}{|c|}{ Penjelas: Klausa Relatif Adverbia } \\
\hline & & & Pre & \multicolumn{4}{|l|}{ Pel } \\
\hline & & & \multicolumn{5}{|c|}{ Frasa Preposisi } \\
\hline & & & $\mathrm{K}$ & & & & \\
\hline
\end{tabular}

\section{Klausa Adverbia (Adverbial Clause)}

\section{Bahasa Indonesia}

(22) Meskipun Andi mempunyai uang banyak, dia selalu hemat.

Tabel 22. Klausa Adverbia

\begin{tabular}{|c|c|c|c|c|c|c|}
\hline Meskipun & Andi & mempunyai & uang banyak, & dia & selalu & hemat. \\
\hline Konjungsi & $\mathrm{S}$ & $\mathrm{P}$ & $\mathrm{O}$ & $S$ & $\mathrm{~K}$ & Pel \\
\hline \multicolumn{4}{|c|}{ Klausa Adverbia (Adverbial Clause) } & \multicolumn{3}{|c|}{ Klausa Utama (Main Clause) } \\
\hline
\end{tabular}

Pada tabel 22 terdapat contoh klausa adverbia. Klausa adverbia tersebut menyatakan konsesif (perlawanan ringan). Di dalamnya terdapat fungsi subjek, predikat, dan objek. Subjek diisi oleh kata benda Andi, predikat oleh kata kerja berkarakter transitif mempunyai, dan objek oleh frasa nomina uang banyak dengan banyak sebagai penjelas dan uang inti. Klausa ini disebut adverbia karena berfungsi sebagai keterangan.

Pola elipsis konjungsi dalam seluruh jenis klausa adverbia tidak berterima dalam Bahasa Indonesia. Ini merupakan salah satu ciri Bahasa Indonesia yang menjadi pembeda dengan klausa adverbia Bahasa Inggris.

\section{Bahasa Inggris}

(23) Although Andi has a lot of money, he is always economical. 
LINGUA, Vol. 14, No. 2, September 2017

p ISSN: 1979 9411; e ISSN: 2442 238X

Http://lingua.pusatbahasa.or.id; Email: presslingua@gmail.com

Center of Language and Culture Studies, Surakarta, Indonesia

Fauziah, Syaid Anisak; Kamal, Mustofa; Djatmika \& Sumarlam. 2017. Perbedaan antara

Klausa Subordinatif Bahasa Indonesia dan Bahasa Inggris.

Lingua (2017), 14(2): 309 324.

Tabel 23. Klausa Adverbia

\begin{tabular}{|c|c|c|c|c|c|c|c|c|}
\hline Although & Andi & has & a lot of money, & he & is & & always & economical \\
\hline Konjungsi & $\mathrm{S}$ & \begin{tabular}{l|l}
$\mathrm{F}$ & $\mathrm{P}$
\end{tabular} & $\mathrm{O}$ & $\mathrm{S}$ & $\mathrm{F}$ & $\mathrm{P}$ & $\mathrm{K}$ & Pel \\
\hline \multicolumn{4}{|c|}{ Klausa Adverbia (Adverbial Clause) } & \multicolumn{5}{|c|}{ Klausa Utama (Main Clause) } \\
\hline
\end{tabular}

Tabel 23 terdapat klausa adverbia. Klausa adverbia tersebut menyatakan konsesif (perlawanan ringan). Di dalamnya terdapat fungsi subjek, predikat, dan objek. Subjek diisi oleh kata benda Andi, predikat oleh kata kerja finit yang tersembunyi dalam kata kerja utama bentuk kini tak berarturan sehingga tidak diketahui ciri kala kininya (s/-es) dan berkarakter transitif has, dan objek oleh frasa nomina a lot of money dengan $a$ lot of sebagai penjelas dan money inti. Klausa ini disebut adverbia karena berfungsi sebagai keterangan.

Pola elipsis konjungsi dalam klausa adverbia yang menyatakan pertentangan ringan kurang berterima dalam Bahasa Inggris. Pola elipsis konjungsi klausa ini jarang ditemui. Pola elipsisis konjungsi klausa adverbia hanya berlaku pada beberapa jenis saja, di antaranya yang menyatakan waktu dan hasil. Bisa jadi, keterbatasan keberterimaan pola elipsis konjungsi klausa adverbia dikarenakan terlalu banyakya jenis klausa ini. Jika diberlakukan pola elipsis konjungsi pada semua jenis klausa adverbial, dimungkinkan terjadinya salah tafsir sehingga pesan penulis tidak tersampaikan kepada pembaca.

\section{Klausa Non-Finit}

\section{Bahasa Indonesia}

Seperti sudah disinggung pada bagian pendahuluan, Bahasa Indonesia tidak mengenal verba finit. Verba finit adalah "bentuk verba yang dibatasi oleh kala dan dalam beberapa bahasa menunjukkan kesesuaian dengan persona" (Kridalaksana, 1993:227). Dari definisi tersebut, yang menjadikan Bahasa Indonesia tidak mempunyai verba finit adalah tidak adanya 'kala'. Kala adalah "pembedaan bentuk verba untuk menyatakan perbedaan waktu atau jangka perbuatan atau keadaan: biasanya dibedakan antara kala lampau, kala kini, dan kala mendatang" (Kridalaksana, 1993:91). Tidak adanya verba finit inilah yang menyebabkan tidak adanya klausa non-finit dalam Bahasa Indonesia. Berikut ini adalah analisis pembuktiannya dengan menggunakan predikat menendang:

Tabel 24. Klausa Non-Finit

\begin{tabular}{|l|l|l|l|}
\hline Arif & kemaren & menendang & bola. \\
\hline S & K & P & O \\
\hline Arif & sekarang & menendang & bola. \\
\hline S & K & P & O \\
\hline Arif & besok & menendang & bola. \\
\hline S & K & P & O \\
\hline
\end{tabular}

Dalam tabel 24, terlihat jelas bahwa kata menendang sama sekali tidak berubah meski dipakai dalam kala lampau kemaren, kini sekarang, dan mendatang besok. Ini 
berbeda dengan Bahasa Inggris. Di bawah ini adalah pembahasan klausa non-finit Bahasa Inggris.

\section{Bahasa Inggris}

Keberadaan klausa non-finit dalam Bahasa Inggris juga sudah disinggung pada pendahuluan. Bahasa Inggris memiliki baik verba finit maupun kala. Kala bahasa ini terdiri dari kala lampau, kala kini, dan kala mendatang. Verba bahasa ini berubah-ubah sesuai dengan kalanya. Berikut ini adalah analisis pembuktiannya dengan menggunakan predikat to kick yang terdapat pada tabel 25 .

Tabel 25. Klausa Non-Finit

\begin{tabular}{|l|l|l|l|l|l|}
\hline Arif & \multicolumn{2}{|l|}{ kicked } & a ball & yesterday. & \\
\hline S & F & P & O & K \\
\hline Arif & kicks & a ball & now. & \\
\hline S & F & P & O & K & tomorrow. \\
\hline Arif & will & kick & a ball. & K \\
\hline S & F & P & O & \multicolumn{1}{l|}{} \\
\hline
\end{tabular}

Pada tabel 25 terlihat jelas bahwa kata to kick berubah ketika dipakai dalam kala lampau kicked, kini kicks, dan mendatang kick. Karena adanya verba finit inilah, terdapat klausa subordinatif non-finit dalam Bahasa Inggris. Klausa subordinatif nonfinit adalah ketidakadaan verba finit dalam sekelompok satuan lingual yang tetap diperlakukan sebagai klausa subordinatif (Miller, 2002:81). Berikut ini adalah contoh analisis klausa subordinatif non-finit:

Georgia regretted slapping Nancy's face.

Tabel 26. Klausa subordinatif non-finit.

\begin{tabular}{|l|l|l|l|}
\hline Georgia & Regretted & slapping & Nancy's face. \\
\hline \multirow{3}{*}{$\mathrm{S}$} & \multirow{3}{*}{} & $\mathrm{P}$ & $\mathrm{O}$ \\
\cline { 3 - 4 } & $\mathrm{P}$ & $\begin{array}{l}\text { O: Klausa Subordinatif Non-finit (Non-finite Subordinate } \\
\text { Clause }\end{array}$ \\
\hline
\end{tabular}

Tabel 26 terdapat klausa subordinatif non-finit. Klausa subordinatif non-finit tersebut menempati fungsi objek. Di dalamnya, terdapat fungsi predikat dan objek. Predikat diisi oleh kata kerja berkarakter transitif slapping dan objek frasa nomina Nancy's face dengan Nancy's sebagai penjelas dan face inti. Di dalam klausa subordinatif non-finit ini, tidak terdapat fungsi subjek dan finit. Ketidakadaan finit itulah yang menyebabkan klausa subordinatif ini disebut non-finit.

\section{SIMPULAN}

Perbedaan antara klausa subordinatif bahasa indonesia dan bahasa Inggris ditemukan dalam beberapa hal sebagai. Semua jenis klausa relatif dan klausa adverbia 
Bahasa Indonesia tidak mempunyai pola pengelipsisan konjungsi. Ini dikarenakan ketidak familiaran pola elipsis tersebut dalam (budaya) Bahasa Indonesia. Selain itu, klausa subordinatif Bahasa Indonesia juga tidak mempunyai jenis non-finit. Ketidakadaan jenis klausa subordinatif non-finit dikarenakan tidak adanya finit dalam Bahasa Indonesia.

Dalam Bahasa Inggris, hanya jenis klausa relatif yang menyatakan kepemilikan yang tidak mempunyai pola pengelipsisan konjungsi. Ini dikarenakan kefamiliaran pola elipsis dalam (budaya) Bahasa Inggris. Tentang klausa adverbia, Bahasa Inggris mempunyai pola pengelipsisan konjungsi pada jenis waktu (temporal) dan hasil (result) saja. Keambiguitasan menjadi alasan utama mengapa tidak seluruh jenis klausa adverbia menerima pola pengelipsisan konjungsi. Selain itu, klausa subordinatif Bahasa Inggris juga mempunyai jenis non-finit. Keberadaan jenis klausa subordinatif non-finit dikarenakan adanya finit dalam bahasa ini.

\section{DAFTAR PUSTAKA}

B., Djuwita Ratna. 2010. “Tipe dan Pola Klausa Subordinatif Bahasa Indonesia”. Sosioteknologi, 20(2):895-922.

Chaer, Abdul. 2007. Linguistik Umum. Jakarta: Rineka Cipta.

Himmawati, Dian Rivia. 2008. "Pola Urutan Frasa Pada Klausa Nominal Bahasa Inggris Dan Bahasa Indonesia”.

Kridalaksana, Hartimurti. 1993. Kamus Linguistik: Edisi Ketiga. Jakarta: PT Gramedia Pustaka Utama.

Mahsun. 2014. Metode Penelitian Bahasa: Tahapan, Strategi, dan Tekniknya. Jakarta: Rajawali Pers

Miller, Jim. 2002. An Introduction to English Syntax. Edinburgh: Edinburgh University Press.

Praptomo, Baryadi. 2003. "Urutan Klausa dalam Kalimat Majemuk Subordinatif Bahasa Indonesia: Kajian dari Perspektif Sintaksis dan Wacana”. Humaniora,19(3):224231.

Santosa, Riyadi. 2014. Metode Penelitian Kualitatif Kebahasaan. Surakarta: UNS Press.

Subroto, Edi. 1992. Pengantar Metoda Penelitian Linguistik Struktural. Surakarta: Sebelas Maret University Press

Sudaryanto. 1993. Metode dan Aneka Tehnik Analisis Bahasa (Pengantar Penelitian Wahana Kebudayaan secara Linguistik). Yogyakarta: Duta Wacana University Press.

Verhaar, J. W. M. 2010. Asas-Asas Linguistik Umum. Yogyakarta: Gadjah Mada University Press. 